\title{
The Use of Cinematic Devices to Portray Mental Illness
}

\author{
Craig Middleton
}

\author{
James Cook University
}

\begin{abstract}
Creative practices that deal with the representation of mental illness potentially have significant social value and relevance; one of these practices is filmmaking and narrative cinema. A film that has recently increased awareness of mental health issues is Silver Linings Playbook (2012). It deals with a family coping with the return of their son, who is being treated for bipolar disorder. "The film gave a fresh face and voice to this issue," said Patrick Kennedy, cofounder of the brain-research organization One Mind for Research (Levin). It garnered multiple awards with the lead actress, Jennifer Lawrence receiving an Oscar for her performance. She used this opportunity to speak out on issues around mental health, "It's just so bizarre how in this world if you have asthma, you take asthma medication. If you have diabetes, you take diabetes medication. But as soon as you have to take medicine for your mind, it's such a stigma behind it" (Paine). As a media form, 'conventional' cinema bears the weight of narrative and genre conventions, both inherent in audience expectations and the filmmakers' desire to 'entertain,' whilst breaking even at the box office. Media critics of the anti-stigma discourse are increasingly bringing our attention to stigmatizing portrayals. However, there are few resources available for filmmakers regarding 'how' to approach faithfully portraying mental illness in the dramatic format of narrative cinema. This research therefore sets out to explore the representation of symptoms associated with mental illness in film, by citing research and commentary relevant to a body of existing films and including specific filmic devices. The findings reveal the fact that there is a significant need for further research into how filmmakers might more faithfully portray symptoms of mental illness in conventional cinema.
\end{abstract}

Contemporary cinema has a difficult task on its hands in attempting to depict the experience of mental illnesss. (M. Anderson)

Since the beginnings of Cinema, early last century, there have been many filmic portrayals of mental illness (Pirkis et al). Yet media studies into the stigmatisation of mental illness date back less than twenty years. This is still a relatively under-researched area and early studies in any academic field tend to be general in scope (Harper, "Media, Madness"). Research of extant literature on the representation of mental illness in films leads to the following broad issues:

- The majority of portrayals perpetuate myths and stereotypes about mental illness and are negative. These portrayals contribute towards the stigmatisation of mental illness (Pirkis et al);

- Portrayals can also be overly positive, suggesting a mental illness can be easily cured, thus contributing towards stigmatisation (Khorrami);

- Some portrayals of mental illness in film are deemed reasonably accurate and therefore suitable for psychiatric teaching purposes (Hyler, "DSM-III");

- Academic anti-stigma criticism: reflects conservative values, relies on a limited definition of violence, can stigmatise popular culture, and tends to be over-generalising (Harper, "Media, Madness"); and

- There is a lack of detailed studies into film techniques used in the representation of mental illness. 


\section{Negative portrayals of mental illness in film}

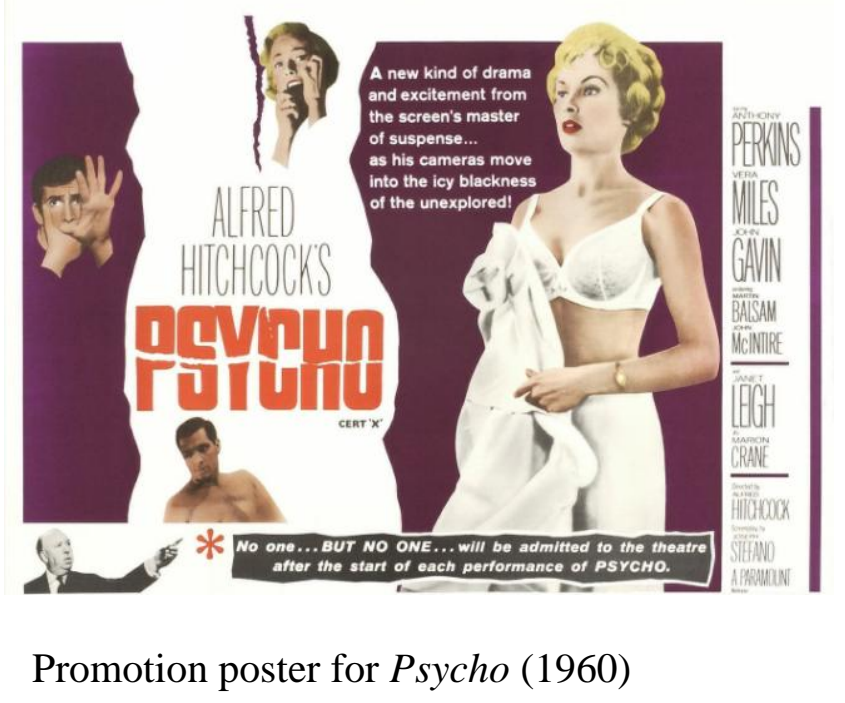

Extant studies argue that fictional films and television programs perpetuate myths and stereotypes about mental illness and such portrayals are overwhelmingly negative. Two potential outcomes of these negative stereotypes are firstly, people experiencing symptoms associated with mental illness are less likely to seek appropriate help, and secondly, negative and inaccurate portrayals contribute towards stigmatisation (Pirkis et al). Eisenhower explains, "Stigma, a literal and metaphorical branding of the body for the purposes of disgrace and condemnation, is about marking the "Other" and delineating boundaries between "us" and "them."

The stigmatisation of people with a mental illness, has a long-established history within visual culture, and remains a current practice: "the creative professionals of today's media are ... just carrying on traditional depictions of the past...the portrayal of the "mad murderer" as looking different activates artistic conventions that have evolved over centuries" (qtd. in Cross). Therefore, this artistic convention of 'displaying the difference' throughout history must have a deep-seated psychological rationale.

Portraying characters with a mental illness as being different and dangerous can serve a psychologically self-protective function (qtd. in Cross). This clear visual separation of the sane and insane indicates the need for instant identification, by society, of the insane. Furthermore, this recognition of a visual stereotype of the insane is based on our construction of images of 'madness' as opposed to the actual illnesses themselves (qtd. in Eisenhower). The need to characterise a person with mental illness is commonly executed in films with a set of visual cues. The signifiers of madness and loss of control, in film and television, are dishevelment, shown as wild, unkempt hair and tattered clothing (qtd. in Nairn).

As early as childhood, viewers are exposed to stereotyped attitudes and terminology that stigmatizes mental illness. A study revealed $85 \%$ of Disney animated films contained verbal references to mental illness. $21 \%$ of the principal characters were referred to as mentally ill. These references were mostly used to distinguish and denigrate the characters to whom they referred (qtd. In Eisenhower) 


\section{Common negative stereotypes of mental illness}

The majority of film portrayals of people with mental illnesses have helped create and reinforce negative stereotypes. The common negative stereotypes are categorised by Hyler et $a l$ and Hyler ("Stigma"). Perhaps the most common and damaging stereotype is the 'homicidal maniac', which associates mental illness with violence. This stereotype was evident over a century ago in The Maniac Cook (1909). Interestingly, the arrival of this stereotype so early in cinema's history, and perhaps a contributing factor to its subsequent prevalence, came from D.W. Griffith. He was a pioneer of narrative cinema and arguably the most influential American film director (qtd in Georgaris).

One of the most famous portrayals of a 'homicidal maniac' is the character of Norman Bates in Psycho (1960). Other 'homicidal maniacs' can be seen in; the Friday the $13^{\text {th }}$ series (1980 and later), the Nightmare on Elm Street series (1984 and later), Silence of the Lambs (1991), Primal Fear (1996), Summer of Sam (1999), American Psycho (2000), Identity (2003) and The Dark Knight (2008). Supernatural elements in films that link mental illness with 'acts of evil' can be found in Halloween (1978) and The Exorcist (1973) (Hyler et al; Hyler "Stigma"). This negative stereotyping reinforces the idea that, "people with a mental illness are aggressive and dangerous to others or themselves" (Pirkis et al).

Other common negative stereotypes of people with mental illness that Hyler et al and Hyler ("Stigma") identify are:

- 'Rebellious free spirit,' seen in One Flew Over the Cuckoo's Nest (1975), Frances (1982) and As Good as It Gets (1997);

- $\quad$ 'Female patient as seductress,' found in Spellbound (1945), Dressed To Kill (1980) and Girl Interrupted (1999);

- $\quad$ 'Enlightened member of society' as in A Fine Madness, (1966) and King of Hearts (1968);

- $\quad$ 'Narcissistic parasite' in Annie Hall (1977), Lovesick (1983), Analyze This (1999) and Analyze That (2002);

- $\quad$ 'Zoo specimen' is found in Bedlam (1946), The Snake Pit (1948) and Zelig (1983); and

- $\quad$ 'Specially gifted' as seen in Rain Man (1988), Shine (1996), K-Pax (2001) and A Beautiful Mind (2001).

Stereotypes can create misconceptions about certain disorders. Me, Myself \& Irene (2000) features Jim Carrey who plays (for laughs) a character with schizophrenia. Carrey's alter ego is aggressive, obscene and sexually disinhibited once he stops taking his medication. The film distorts the facts regarding schizophrenia: it is a non-violent illness (Bryne, "Schizophrenia"), and the split or multiple personality depicted in the film belongs to a dissociative disorder, not the psychotic illness, schizophrenia (Baron-Faust). Furthermore, the film's target audience age group is fifteen to twenty-four years old. This age group has the peak incidence of schizophrenia. A possible outcome of this film is that, people with this illness are deterred from seeking help for fear of stigmatisation, as the film clearly links schizophrenia with violence and other disturbing anti-social behaviour (Bryne, "Schizophrenia"). 


\section{Striving for accurate portrayals of mental illness}

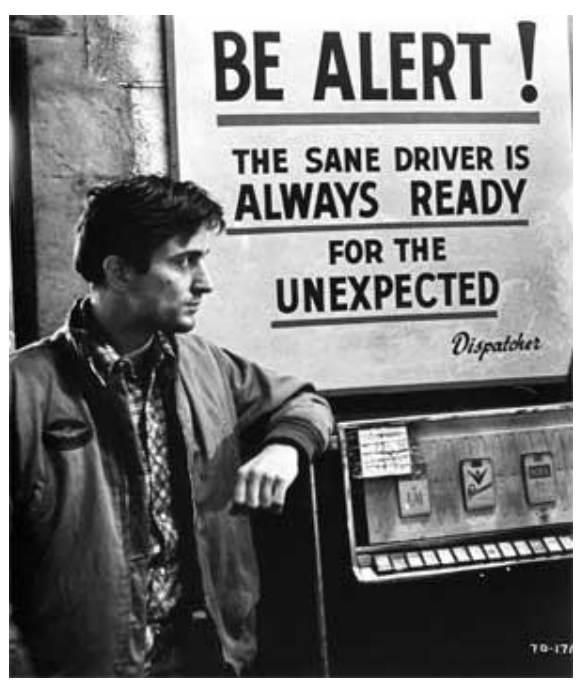

Taxi Driver (1976)

More authentic portrayals of people with a mental illness may function to counterbalance the many negative and inaccurate portrayals of mental illness in film. The problem with representing mental illness in film is that dramatic effect can often compromise a concern with accuracy (Hyler et al). Reasonably accurate portrayals of mental disorder exist, and some films may benefit members of the psychiatry industry, as tools to supplement readings on diagnosis (Hyler "DSM-III"; Rosenstock).

Selected films are identified and examined in terms of DSM-III diagnostic criteria by Hyler ("DSM-III"). In the case of Taxi Driver (1976), the protagonist, Travis Bickle "displays ideas of reference and paranoid ideation that become delusional in intensity.... The character's premorbid personality would, according to DSM-III, certainly meet the criteria for schizotypal personality" (Hyler "DSM-III"). Other films that are examined through diagnostic criteria by Hyler ("DSM-III") and Hyler et al are:

- $\quad$ Sophie's Choice (1982) for bipolar disorder;

- It's a Wonderful Life (1946) and The Wrong Man (1957) for major depression;

- $\quad$ The Lost Weekend (1945) and The Man with the Golden Arm (1956) for substance dependence and substance-induced mental disorder;

- $\quad$ Spellbound (1945) and The Three Faces of Eve (1957) for dissociative disorders;

- $\quad$ Vertigo (1958) for personality disorder;

- $\quad$ Ordinary People (1980) for anxiety disorder;

- $\quad$ Citizen Kane (1941), Lawrence of Arabia (1962) Alfie (1966), Shampoo (1973), American Giggolo (1980) for Narcissistic personality disorder;

- $\quad$ Looking for Mr. Goodbar (1977), After Hours (1985) and Frances (1982) for borderline personality disorder;

- A Clockwork Orange (1971) for antisocial personality disorder; and

- $\quad$ Blue Velvet (1986) for dependent personality disorder. 
Teaching about schizophrenia, using certain films that deal with the mental disorder is a practice recommended to psychiatric educators by Rosenstock. This selected filmography includes: A Beautiful Mind (2001), Clean, Shaven (1995), Angel Baby (1995), An Angel at My Table (1990), Birdy (1984), The Cabinet of Dr. Caligari (1919), Invasion of the Body Snatchers (1956), Possessed (1947), The Saint of Fort Washington (1993), and The Fisher King (1991). However, psychiatric educators are warned to exercise caution when selecting which films to use for teaching. A bad example being Me, Myself \& Irene (2000), as the film distorts the facts regarding schizophrenia (Bryne, "Schizophrenia"). Furthermore, educators should select appropriate scenes, as some films listed contain inaccurate information. $A$ Beautiful Mind (2001) is criticised by Rosenstock for its heavy use of dramatic license and for being overly positive in its portrayal of mental illness.

\section{Overly positive portrayals}

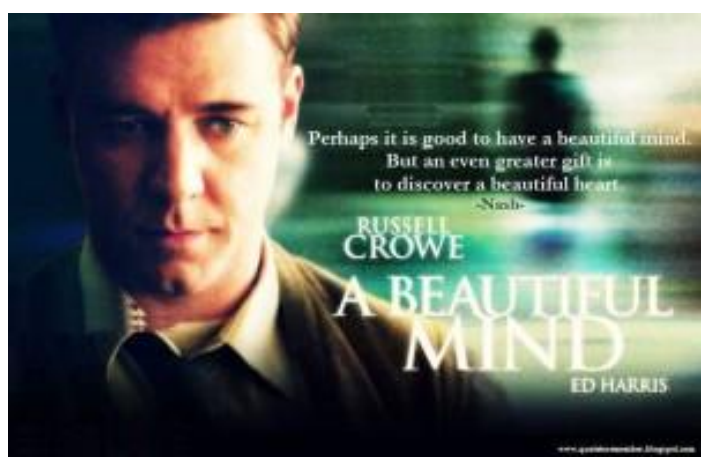

A Beautiful Mind (2001)

Overly positive images in portrayals of mental illness in films contribute to stigmatization. Conversely, the positive images presented of overcoming a mental illness in A Beautiful Mind (2001) and Shine (1998), work to reinforce a common negative stereotype, the 'specially gifted,' as identified by Hyler et al. Both films send out the troubling message that mental illness is curable by the love of a good woman (Khorrami).

Movie biopics such as A Beautiful Mind (2001) can be criticised for sanitising its real life subject. The real John Nash was arrested for soliciting homosexual sex. The film conveniently omits any speculation over Nash's sexuality (Harper, "Understanding"). This form of sanitising can be problematic, as Shohat and Stam argue (qtd. in Harper "Understanding"), "a cinema of contrivedly positive images betrays a lack of confidence in the group portrayed, which usually itself has no illusions concerning its own perfection." The glossing over of inconvenient facts in A Beautiful Mind (2001) illustrates perfectly the financial and commercial considerations involved when producing a commercial Hollywood movie, as the director Ron Howard implicitly suggests, "Many, many aspects of his life have been simplified, shaped, and made into a movie story" (Murray and Topel). Therefore, the process of making a movie story means that authenticity can lose over box office appeal. Interestingly, recurrent gender-based stereotypes are revealed within this film subgenre, the biopic. The overly positive message of disturbed geniuses experiencing enlightenment only applies to the male protagonists in these films. The female protagonists in Sylvia (2003), Iris (2001) and The Hours (2002) are denied any sort of happy ending. Plus, little is revealed about the life work of the female protagonist, while the achievements of the male protagonists are celebrated within the film. The lack of images of female genius in these 
recent films reveals a sexist tradition influencing contemporary representations of mental illness based on gender (qtd. in Harper "Understanding").

\section{Criticisms of anti-stigma discourse}

Academic anti-stigma criticism has a number of outcomes: it integrates conservative values into the premise of evaluating images, it relies on a limited definition of violence, and it can derogate the popular culture from which these representations of mental illness are sourced and tends be over-generalising (Harper "Media, Madness"). Weaknesses in argumentation, as well as theoretical weaknesses, are discussed by Harper ("Media, Madness") mainly using Otto Wahl's widely cited Media Madness.

Firstly, Wahl injects conservative opinions into the studies, and some can even help to stigmatise popular culture. This moralism affects the reading of images within popular texts. The failure to acknowledge any cultural value in, or progressive aspects of, the text the representation is found in causes oversights when viewing portrayals. Wahl dismisses slasher films, a subgenre of horror, as 'gratuitous' and rife with violent anti-feminism. An archetypal narrative device of the slasher genre, the 'final girl' trope, seen in Halloween (1978) and a Nightmare on Elm Street (1984), is ignored. The 'final girl' aspect of the slasher genre is potentially progressive and is considered by Carol J. Clover (qtd. in Harper, "Media, Madness"), who coined the term, 'final girl,' to be a feminist aspect of this popular text. The lack of insight into the workings of a film genre is evident here. Surely that could cause concern, as it does for Harper ("Media, Madness"), if such oversights are made in evaluating images of representation.

Secondly, there is no consideration from anti-stigma discourse that violence can be positive, progressive and resistive. This is evident in their identification of stereotypes that link mental illness with violence. This oversight means that the relevance of the context in which the violence is set, is not considered. The film Taxi Driver (1976) for example, deals with the psychological implications of social alienation. A person's descent into psychotic violence is set in the context of a Vietnam War veteran struggling to cope in a rotten, exploitative and hypocritical society (Harper "Media, Madness"). This Is England (2006) follows a mentally unstable ex-convict and culminates in an explosive act of violence. This violence is shown in the context of social inequality, imprisonment and the inference of an abusive childhood which are social forms of violence. Therefore, we understand that the violence perpetrated is a consequence of the character's upbringing and environment. (Harper "Media, Madness") These films do not stigmatise mental illness, in their relation to violence, once examined in a social context.

Thirdly, an obsession with verisimilitude, or representational accuracy, when evaluating representations of mental illness may cause anti-stigma writers to misread films as serious studies of mental illness, preventing them from considering how madness can be used metaphorically as expressions of political and social protest (Harper "Media, Madness"). Filmmakers often use genre films, such as the horror or psychological thriller genre, to deliver personal statements or comment on social issues. In Donnie Darko (2001), a teenager's presumed mental illness is seen as society's way of constraining 'antisocial' behaviour. Mental disturbance becomes a metaphor for, respectively, feminist empowerment and the alienation of the war veteran in Gothika (2003) and The Jacket (2005). The 
protagonists of these films are presented as sane people living in a 'crazy' world (Harper "Media, Madness"; "Understanding").

Lastly, there is a risk of over-generalising when such a wide range of popular texts and genres is used, as with Wahl's studies, in identifying portrayals of mental illness. This method homogenises the sourced materials, and evaluations of 'positive' and 'negative' become problematic if not considering factors of difference between the exigencies of media forms and genres, and the social context in which the portrayal is set, especially if violence is associated with mental illness in the text. However, the generalizing tendency evident in the work of the anti-stigma discourse is acknowledged by Harper ("Media, Madness") as a necessary aspect of studies at an early stage in a relatively under-researched area.

\section{Film Techniques}

Further studies regarding film techniques used in the representation of mental illness will contribute strongly to the anti-stigma discourse. Media critics are encouraged by Camp et al to acquire a greater understanding of the way filmic devices, including; "appearance, music and sound effects, lighting, language, shot selection and editing, horror conventions, and intertextuality", are used in the portrayal of 'madness'. This deeper knowledge will further enable critics in identifying and combating recurring images that stigmatize mental illness. Furthermore, it will enhance the capacity to examine portrayals of mental illness in their institutional and cultural-historical context (Camp et al).

Filmic devices relate to the technical and creative aspects of filmmaking. Aspects that take place in front of the camera, such as lighting, are considered elements of mise-en-scène (putting into the scene). The four main elements of mise-en-scène are: setting, lighting, staging: movement and performance, and costume and make up. Film editing and scoring are not considered part of mise-en-scène but both are crucial in defining both the style and content of a film.

In a study of two pivotal sequences featuring the Joker in The Dark Knight (2008), six film techniques employed to convey the Joker's madness are identified. Techniques including jump cutting, POV (point of view) shots, intercutting and use of colour were deemed effective in the construction of a film character that "physically incarnates madness" (Camp et al).

Some authors identify film techniques that illustrate how a character with mental illness is presented differently than other characters. Studies by Pirkis et al list five filmic devices, "the individual point of view, close-up shots, discordant music, atmospheric lighting, setting selection and scene juxtapositions."

A more detailed analysis from Rose, using scenes from a sample of UK television programmes, illustrates how a combination of close-ups and extreme close-ups socially isolate characters with a mental illness, thus 'displaying their difference.' Furthermore, Rose illustrates how the use of filmic devices such as; camera shots (close ups, extreme close-ups and aerial shots), camera movement (in particular, a tracking shot that moves through the scene), and shot duration (the length of a shot), all work to introduce a sense of danger into scenes featuring a character with mental illness. 
Some filmmakers are commended for their creative effort in using filmic devices to represent a character's experience of symptoms often associated with mental illness. Interestingly, the following literature cited all deals with non-commercial films that portray a character's symptoms of schizophrenia. The "depiction of Ray's descent into perplexity and paranoia, with poorly formed auditory hallucinations," in Some Voices (2000) is praised by Byrne. The "continual sound distortion and radio "fuzz" that simulate auditory hallucinations" created in Clean Shaven (1995) allowed "viewers to 'get inside the head' of people with schizophrenia," (Rosenstock 2003, p. 119). Similarly, Harper ("Understanding") claims that the film Spider (2002), "brilliantly reproduces the idioglossic speech of those diagnosed with schizophrenia." Moreover, the use of audio effects to represent schizophrenia, plus other filmic devices such as, using handheld cameras in real-life environments in Julien donkeyboy (2001) and Keane (2004), not only creates a realistic subjectivity of mental disturbance, but presents "mental distress in new ways" (Harper, "Understanding").

There is some extant brief analysis in the literature that's insightful as to how filmic devices are used in both the representation of mental illness, and more specifically, a character's experience of symptoms often associated with mental illness. However, the filmic terminology used is basic and limited. Furthermore, the descriptive language used is potentially vague, for example "the filmmakers have made full use of the Dolby digital soundtrack" (Bryne, "Some Voices"), and "intensified by jump-cutting between the roof, the street, the bank interior, and the vault." (Camp et al). The term, intercutting, which is referred to elsewhere in the Camp et al study, is clearly more suitable than the term, jump-cutting, used in this instance.

\section{Conclusion}

In terms of the representation of mental illness in film, including specific filmic devices employed by filmmakers, the following general principles can be identified:

- While there is some extant research regarding fictional film portrayals of mental illness, many gaps in knowledge exist (Pirkis);

- $\quad$ Critical modifications to anti-stigma discourse are needed. Media critics, according to Harper ("Media, Madness"), must carefully examine both the premises and outcomes of the arguments they use to counterattack stigmatizing portrayals of mental illness;

- $\quad$ Although some contemporary filmmakers are portraying mental illness in new, progressive ways, there are few resources available in terms of representing mental illness from a filmmaker's perspective. Most relevant studies tend to come from a medical or sociological background. There is no manual for filmmakers that investigates a set of techniques that can be employed in the production of a film to portray a character experiencing symptoms often associated with mental illness; and

- $\quad$ A deeper knowledge of these filmmaking aspects will enable filmmakers interested in portraying mental illness, and anti-stigma writers with a greater capacity to recognise, evaluate and counterattack stigmatising portrayals of mental illness in film.

More resources are needed that will enable filmmakers to investigate 'progressive' filmic 
devices to faithfully portray mental illness symptoms in the dramatic format of narrative cinema. This will contribute towards the destigmatization of mental illness in film. In order to identify 'progressive' filmic devices, much further research is needed in two areas:

- $\quad$ Empirical research of existing bodies of films, involving detailed analysis of specific filmic devices used to represent mental illness. This will create the opportunity for filmmakers to reconsider using existing sets of clichéd techniques that, throughout the history of cinema and visual culture (Cross), have contributed towards stigmatization.

- $\quad$ The creation of new stories and 'new' filmic devices within cinema. Filmmakers experimenting with 'new ways' of representing mental illness so they can more faithfully portray symptoms.

As mental health continues to have an impact in society, it is important that filmmakers continue to strive to achieve increasingly faithful and non-stigmatizing portrayals.

\section{Works Cited}

Anderson, M. "'One Flew Over the Psychiatric Unit': Mental Illness and the Media." Journal of psychiatric and mental health nursing 10.3 (2003): 297-306. Web. 22 Mar 2012.

Baron-Faust, Rita. Me, Myself \& Irene [Film]. 321 Vol. BMJ Publishing Group, 2000. Web. 22 Feb 2012.

Byrne, Peter. Some Voices [Film]. 321 Vol. BMJ Publishing Group, 2000. Web. 22 Feb 2012.

Byrne, P. "Schizophrenia in the Cinema: Me, Myself and Irene." Psychiatric Bulletin 24.10 (2000): 364-5. Web. 21 Jun 2012.

Camp, M. E; Webster, C. R, Coverdale T. R, Coverdale J. H, Nairn. "The Joker: A Dark Night for Depictions of Mental Illness." Academic Psychiatry: the journal of the American Association of Directors of Psychiatric Residency Training and the Association for Academic Psychiatry 34.2 (2010): 145-9. Web. 21 Sept 2012.

Cross, S. "Visualizing Madness: Mental Illness and Public Representation." Television \& New Media 5.3 (2004): 197-216. Web. 12 Feb 2012.

Eisenhauer, Jennifer. "A Visual Culture of Stigma: Critically Examining Representations of Mental Illness." Art Education 61.5 (2008): 13. Web. 22 Feb 2012.

Georgaris, B. THEY SHOOT PICTURES, DON'T THEY? (TSPDT). 2013. Web. 21 Oct 2013

Harper, S. "Media, Madness and Misrepresentation: Critical Reflections on Anti-Stigma Discourse." European Journal of Communication 20.4 (2005): 460-83. Web. 22 Feb 2012. 
Harper, Stephen. "Understanding Mental Distress in Film and Media: A New Agenda?" The Journal of The Royal Society for the Promotion of Health 128.4 (2008): 170-4. Web. 22 Feb 2012.

Hyler, Steven E. "DSM-III at the Cinema: Madness in the Movies." Comprehensive Psychiatry 29.2 (1988): 195-206. Web. 23 Feb 2012.

Hyler, S. E., Gabbard, G.O. and I. Schneider. "Homicidal Maniacs and Narcissistic Parasites: Stigmatization of Mentally Ill Persons in the Movies." Hospital \& community psychiatry 42.10 (1991): 1044-8. Web. 24 Feb 2012.

Hyler, Steven H. "Stigma Continues in Hollywood." Psychiatric Times. N.p., 3 June 2003. Web. 17 Mar 2013.

Khorrami, Sam. "Genius, Madness, and Masculinity: A Beautiful Mind Examined through a Men's Issue Model." Men and Masculinities 5.1 (2002): 116-8. Web. 22 Feb 2012.

Levin, Aaron. "Oscar-Nominated Film does More than Entertain." Psychiatric News 48.6 (2013): 17. Web. 22 Sept 2013.

Murray, Rebecca, and Fred Topel. "Ron Howard Interview-Director of "A Beautiful Mind." Movie Reviews, Trailers, Film Photos, News, and Interviews - About.com. N.p., n.d. Web. 12 Mar 2012.

Nairn, RG. "Media Portrayals of Mental Illness, Or is it Madness? A Review." Australian Psychologist 42.2 (2007): 138-46. Web. 22 Feb 2012.

Paine, Chris. "Silver lining: Oscars darling Jennifer Lawrence may 'save lives' | News.com.au." News.com.au | News Online from Australia and the World | NewsComAu. N.p., n.d. Web. 16 Oct. 2013. Web. 22 Feb 2013.

Pirkis, Jane, R Warwick Blood, Catherine Francis, and Kerry McCallum. A review of the literature regarding fictional film and television portrayals of mental illness. Melbourne: The University of Melbourne, 2005. Web. 22 Feb 2012.

Rhodes, Eric Bryant. "Lost Highway. David Lynch, Deepak Nayar, Tom Sternberg, Mary Sweeney." Film Quarterly 51.3 (1998): 57-61. Web. 22 Mar 2012.

Robey, Tim. "Oscars 2013: The real reason David O Russell made Silver Linings Playbook Telegraph."Telegraph.co.uk - Telegraph online, Daily Telegraph, Sunday Telegraph Telegraph. N.p., 23 Feb. 2013. Web. 21 Sept. 2013.

Rose, Diana. "Television, Madness and Community Care." Journal of Community \& Applied Social Psychology 8.3 (1998): 213-28. Web. 22 Feb 2012.

Rosenstock, Jason. "Beyond a Beautiful Mind: Film Choices for Teaching Schizophrenia." Academic psychiatry: the journal of the American Association of Directors of Psychiatric Residency Training and the Association for Academic Psychiatry 27.2 (2003): 117-22. Web. 24 Feb 2012. 
Shohat, Ella, and Robert Stam. Unthinking Eurocentrism: multiculturalism and the media. London; New York: Routledge, 1994. Web. 02 Feb 2012.

Wahl, Otto F. Media madness public images of mental illness. New Brunswick, NJ: Rutgers University Press, 1997. Web. 12 Sept 2012. 